\title{
Research of multi component response characteristics of array antenna source transient electromagnetic tunnel detection
}

\author{
Guo Jianlei, Li Xiu* \\ Chang'an University \\ College of Geology Engineering and Geomatics \\ Xi'an, China
}

\begin{abstract}
Water channel detection has become the focus and difficulty of tunnel detection because of needing a higher resolution. We put forward the array antenna source transient electromagnetic tunnel detection method on the basis of radar array antenna. Firstly, it verifies that the array antenna source has better recognition ability than small loop and tests the advantages of horizontal component than vertical component of water-bearing geologic structure detection. Influence of array transmitter scale, source length and source spacing on different components of the transient electromagnetic data is analyzed, and concludes the influence of the distance between fault and tunnel surface, thickness of the fault, the fault and surrounding rock resistivity difference and other parameters of the response characteristics under the same antenna array source.
\end{abstract} component

Keywords- array antenna, TEM, tunnel detection, three-

\section{INTRODUCTION}

Water inrush and mud is one of the serious geological disasters in tunnel construction, the main source of disaster triggering the water inrush and mud including fault, karst cave underground type and fractured. Between the sources of disaster or the source with the terrestrial lakes and rivers is along with each other in the form of water channel, Fissure hazard source formats big confined water owning to the rock pressure, so fissure hazard source and water channels often cause water gushing and even cause the irreversibility of the ecological system. If the specific location of fissure disaster source and water channel can be accurately detected, it will be able to advance take effective measures to prevent disasters. The accurate detection of water channels and fissure hazard source need high detection resolution.

The existing geophysical exploration techniques usually cannot reach the purpose of exploration because of insufficient resolution. Therefore, we put forward the array antenna source transient electromagnetic tunnel detection method to probe water channel, this method layouts electrical source used as the emission source and multiple receiving point as signal acquisition on the tunnel face as a working way of multisource emission and multi point observation. Multi electrical source transmitting at the same time can not only maximizes the energy concentrated in front of the tunnel face, improving the signal-to-noise ratio, but also use the relative position between each electric source and adverse geological body to better resolute unfavorable geologic bodies; multi point observation can effectively increase the amount of data collected and better reflect 3D scale and spatial distribution of the abnormal body in the front of the tunnel face; while shortening the pulse width to increase exploration frequency to improve the solution based on the above disciplinarian, to lay the foundation for the practical application of detecting water channel. The method's advantages are verified and the related parameters are analyzed based on the common disaster because of that the method is proposed firstly. It verifies that the antenna array source has better recognition ability than small loop and tests the advantages of horizontal component than vertical component of water-bearing geologic structure detection through the three dimensional numerical simulation. And the influence of array source parameters and fault parameters on the response characteristics are analyzed, then, verifying that this method has important significance for improving the detection accuracy of transient electromagnetic super forecast.

\section{II.ANALYSIS TEM RESPONSE CHARACTERSTICS OF DIFFERENT EMISSION SOURCE}

Design the following tunnel model: the tunnel is $6 \mathrm{~m}$ high, width of $6 \mathrm{~m}$, ahead of the tunnel face is a vertical fault, fault dimension is $50 * 50 * 5 \mathrm{~m}$, located in front of tunnel face $40 \mathrm{~m}$, the resistivity of surrounding rock for $100 \Omega \cdot \mathrm{m}$, fault resistance of $5 \Omega \cdot \mathrm{m}$; respectively using array antenna source of $3 * 3$ and small loop source as the emission source placed in the middle of the tunnel face. Array antenna source parameters are as follows: source $1 \mathrm{~m}$ in length and the spacing between the source with source is $0.2 \mathrm{~m}$, the emission current $1 \mathrm{~A}$; loop source parameters are as follows: square loop source length $3 \mathrm{~m}$, the emission current of $1 \mathrm{~A}$, source array measuring points deviate from the array antenna source center $0.1 \mathrm{~m}$ and loop source measuring points located in the center of the source of the loop, the two measuring point response values are compared and analyzed.

Loop source $\mathrm{z}$ component curve cannot distinguish fault, but the three components of the array antenna source have obvious anomalies at this time and anomalous time also relatively earlier, which verify the source array has better recognition ability than loop source of abnormal structure. The model is about $\mathrm{x} / \mathrm{y}$ axial symmetry, so the $\mathrm{x}$ and $\mathrm{y}$ components have the 


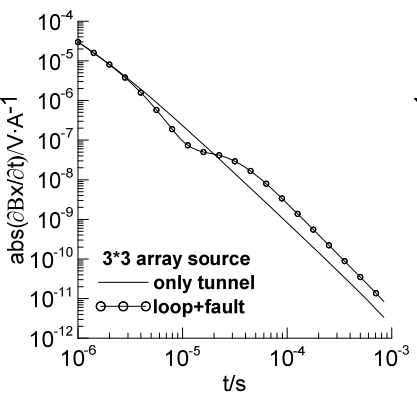

(a) $\mathrm{x}$ component

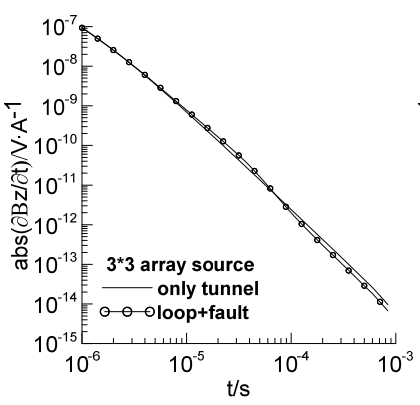

(c) $\mathrm{z}$ component

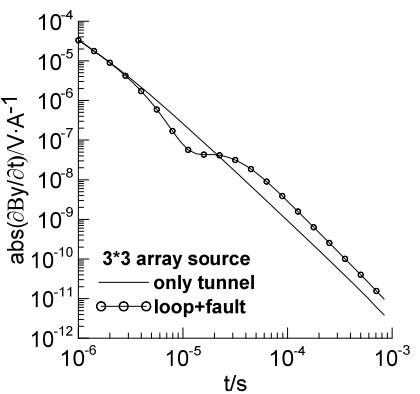

(b) y component

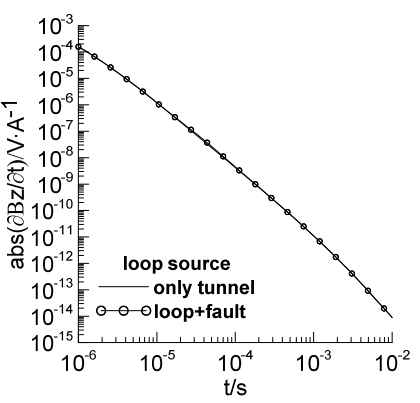

(d) z component

Fig. 1 array antenna source $(\mathrm{a} / \mathrm{b} / \mathrm{c})$ with small loop source response (d)

same curve, and the horizontal component of the response force is greater than the vertical component.

\section{III.ANALYSIS INFLUENCE OF PARAMETERS OF ARRAY ANTENNA SOURCE AND FAULT ON RESPONSE CHARACTERISTICS}

It changes these six parameters including array antenna source scale, source length, source and source distance, distance between fault and tunnel face, slice thickness, difference of fault and surrounding rock resistivity, to do 3D FDTD forward modeling and to analyze the influence on the response characteristics.

\section{IV.EFFECT OF ARRAY ANTENNA SOURCE SCALE ON RESPONSE CHARACTERISTICS}

Design parameters of the model as follows: the tunnel is $6 \mathrm{~m}$ high, width of $6 \mathrm{~m}$, ahead of the tunnel face is a vertical fault, fault dimension is $50 * 50 * 5 \mathrm{~m}$ and resistivity of surrounding rock for $100 \Omega \cdot \mathrm{m}$, fault resistance of $1 \Omega \cdot \mathrm{m}$, change the array antenna source scale into $1 * 1,3 * 3,5 * 5,7 * 7$, source length is $1.2 \mathrm{~m}$, source spacing is $0.2 \mathrm{~m}$, the emission current is $50 \mathrm{~A}$, the calculation of three situations that is pure tunnel cavity and fault from the tunnel face 20 meters, 50 meters.

When increasing the scale of the array antenna source, the transient electromagnetic response curve is basically the same, and the response force increases is a simple linear relationship with array source scale increases; when the distance between fault and the tunnel face is the same, each component of the morphological response does not change with changes in the array source scale; reducing the distance of fault and tunnel face, the anomaly characteristics of the components become more and more obvious; when the distance is far, $\mathrm{x}$ component has a better resolution than the $\mathrm{z}$ component.

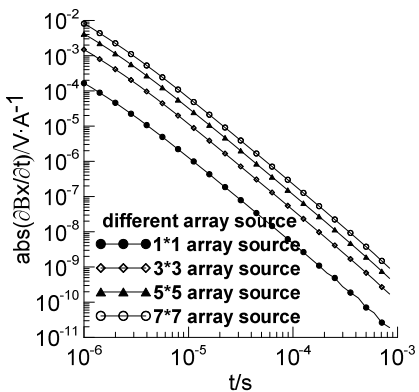

(a) tunnel $x$ component

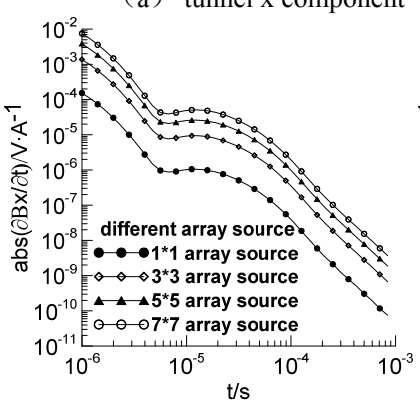

(c) $20 \mathrm{~m} \times$ component

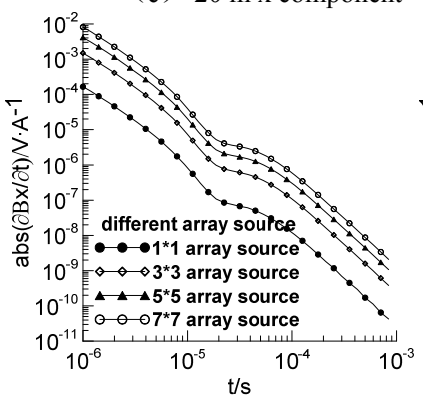

(e) $50 \mathrm{~m} \times$ component

Fig 2. change of array antenna source scale

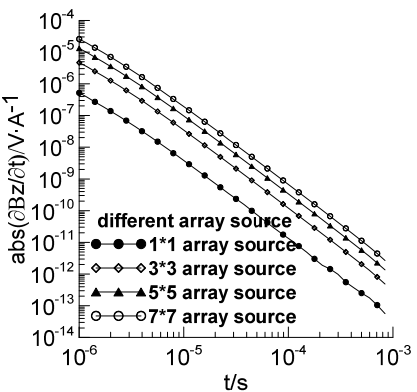

(b) tunnel z component

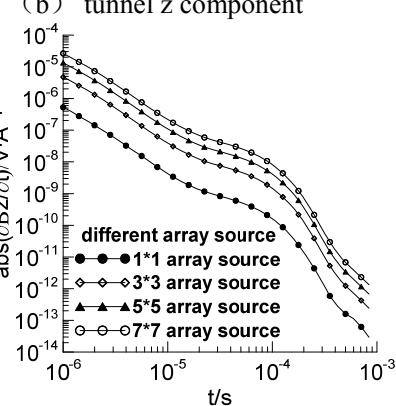

(d) $20 \mathrm{~m} \mathrm{z}$ components

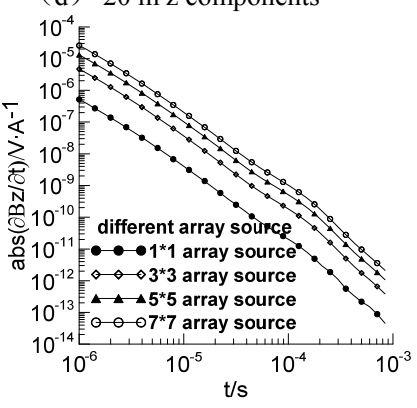

(f) $50 \mathrm{~m} \mathrm{z}$ components

\section{V.EFFECT OF SOURCE LENGTH ON RESPONSE CHARACTERISTICS}

By adopting the above model of the tunnel, array antenna source scale is $3 * 3$, source spacing is $0.2 \mathrm{~m}$, change the source length of $0.6 \mathrm{~m}, 1.2 \mathrm{~m}$, the calculation of three situations that is pure tunnel cavity and fault from the tunnel face 20 meters, 50 meters.

The transient electromagnetic $\mathrm{x}$ and $\mathrm{z}$ component response curves are almost unchanged while changing the source array source length; and the response force increases is a simple linear relationship with source length increases; when fault location is fixed, the response curve shape does not change with the change of the source length.
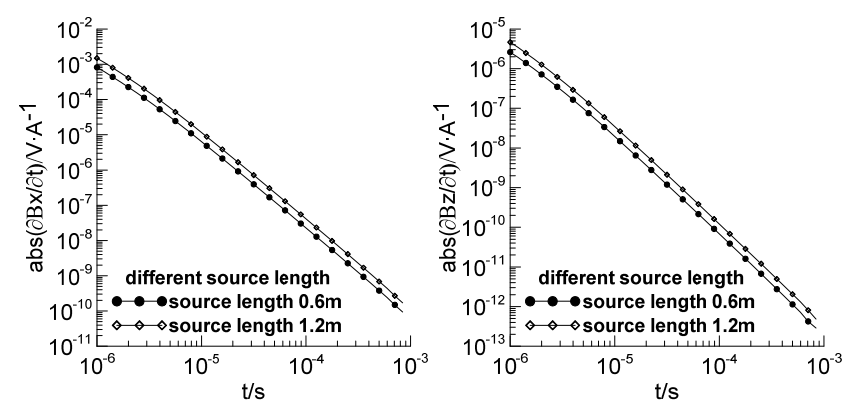
(a) tunnel x component

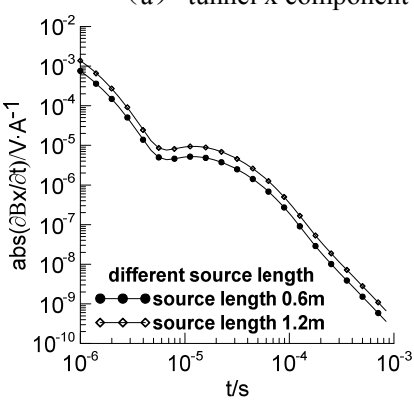

(c) $20 \mathrm{mx}$ component

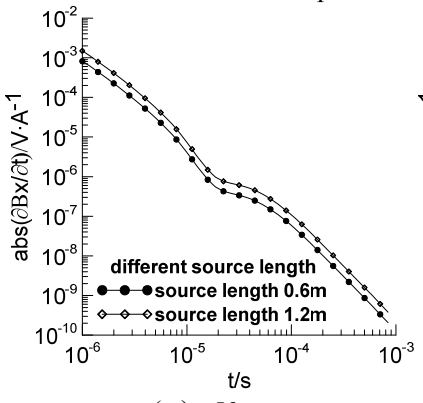

(e) $50 \mathrm{~m} \times$ component

Fig. 3 change of antenna array source length
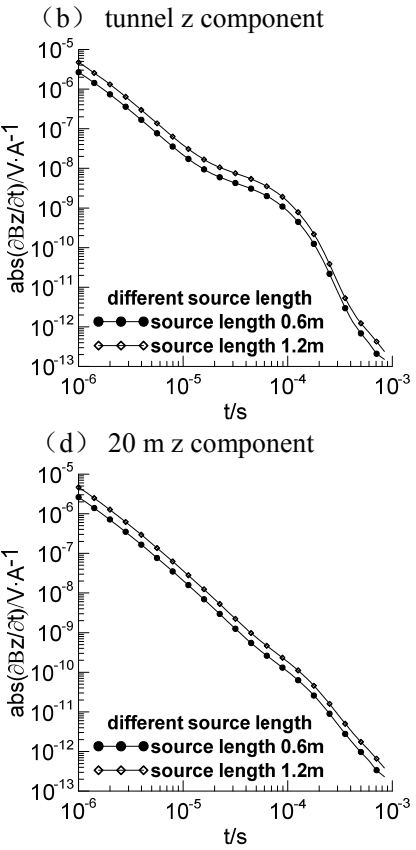

(f) $50 \mathrm{~m} \mathrm{z}$ component

\section{VI.EFFECT OF SOURCE SPACING ON THE RESPONSE CHARACTERISTICS}

Using the above model, array antenna source scale is $3 * 3$, source length is $0.6 \mathrm{~m}$, changing source spacing $0.2 \mathrm{~m}, 0.6 \mathrm{~m}$, $1.2 \mathrm{~m}$, the calculation of three situations that is pure tunnel cavity and a fault from the tunnel face $20 \mathrm{~m}, 50 \mathrm{~m}$.

Changing source spacing, transient electromagnetic $\mathrm{x}$ and $\mathrm{z}$ component response curves are almost overlapped when the spacing is $0.2 \mathrm{~m}$ and $0.6 \mathrm{~m}$; the force of the response is slightly increased when the source spacing increases to $1.2 \mathrm{~m}$; the transient electromagnetic response characteristic curves are the same under these three spacing.

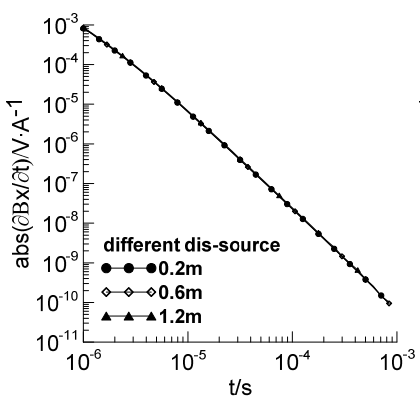

(a) tunnel $\mathrm{x}$ component

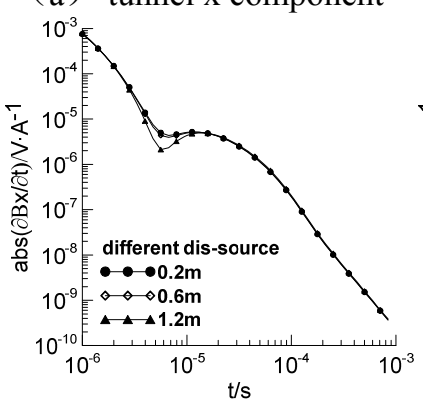

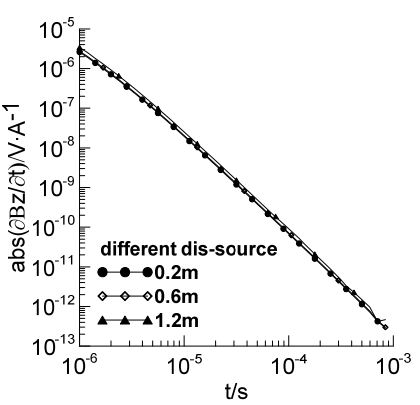

(b) tunnel $\mathrm{z}$ component

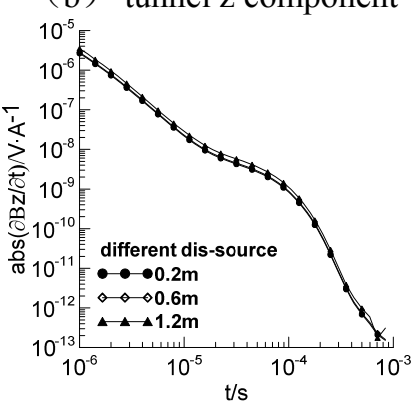

(c) $20 \mathrm{mx}$ component

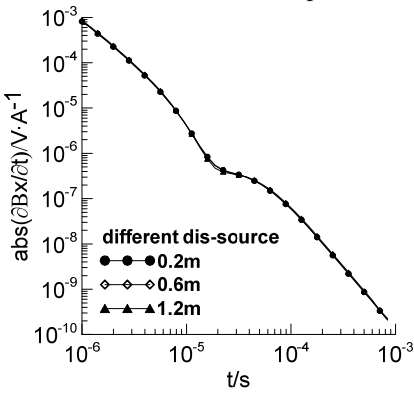

(e) $50 \mathrm{mx}$ component

Fig. 4 change of source spacing

\section{VII.EFFECT OF THE DISTANCE BETWEEN FAULT AND TUNNEL FACE ON RESPONSE CHARACTERISTICS}

Using the above model, array antenna source scale is $3 * 3$; source length is $0.6 \mathrm{~m}$, source spacing is $0.2 \mathrm{~m}$, change the distance of faults and tunnel surface into $5 \mathrm{~m}, 20 \mathrm{~m}, 50 \mathrm{~m}, 60 \mathrm{~m}$.

$\mathrm{Z}$ component curve characteristics anomaly is obvious when the distance of fault and tunnel face is less than $50 \mathrm{~m}$; at the $50 \mathrm{~m}$, fault can be seen roughly, , but the curve almost coincide with pure tunnel cavity response curve when more than $60 \mathrm{~m}$, and $\mathrm{z}$ component curve in faults always presents a "bulge" form; when fault from the tunnel face closely, the $\mathrm{x}$ component curve anomalies consistent almost is same with $\mathrm{z}$ component anomaly curve characteristics; when the distance is far, the $\mathrm{x}$ component of the curve show ' $\mathrm{S}$ ' form, so, the distance between fault and tunnel face can be roughly determined according to the characteristics. The of $\mathrm{x}$ component curve anomaly characteristics is still evident compared to the $\mathrm{z}$ component at long distance, which proves once again that $\mathrm{x}$ component has higher sensitivity than the $\mathrm{z}$ component.

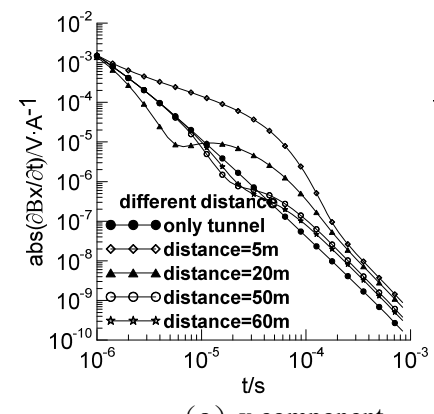

(a) x component

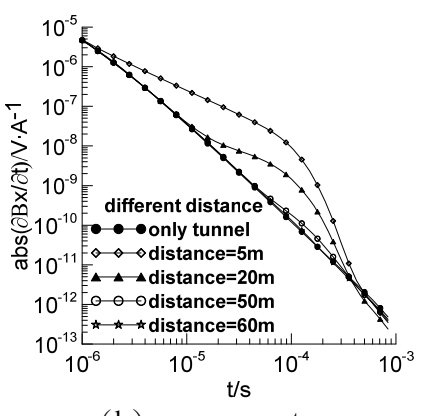

(b) z component

Fig. 5 change the distance of fault and tunnel face

\section{VIII.EFFECT OF FAULT THICKNESS ON THE RESPONSE CHARACTERISTICS}

Using the above model, change the fault thickness into $5 \mathrm{~m}$, $10 \mathrm{~m}, 15 \mathrm{~m}, 20 \mathrm{~m}$, and fault from the tunnel face is $50 \mathrm{~m}$.

The thickness of the fault is greater, the $\mathrm{x}$ and $\mathrm{z}$ component curve anomaly characteristics are more obvious and have longer abnormal duration; the curve anomaly is at the same time because the distance between fault and tunnel face is the same. 


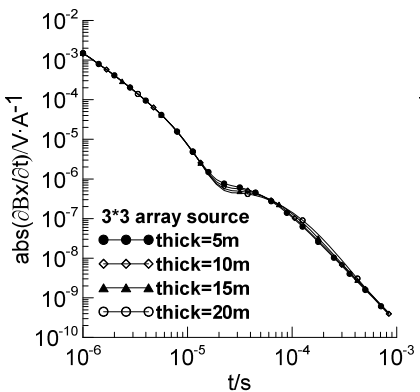

(a) x component

Fig. 6 change of fault thickness

\section{IX.EFFECT OF RESISTIVITY DIFFERENCES OF FAULT AND SURROUNDING ROCK ON RESPONSE CHARACTERISTICS}

Using the above model, change the fault resistivity into $1 \Omega \cdot \mathrm{m}, 5 \Omega \cdot \mathrm{m}, 10 \Omega \cdot \mathrm{m}, 30 \Omega \cdot \mathrm{m}$, and the distance between fault and tunnel face is $50 \mathrm{~m}$.

The thickness of the fault is greater, the $\mathrm{x}$ and $\mathrm{z}$ component curve anomaly characteristics are more obvious and have onger abnormal duration; the curve anomaly is at the same time because the distance between fault and tunnel face is the same.
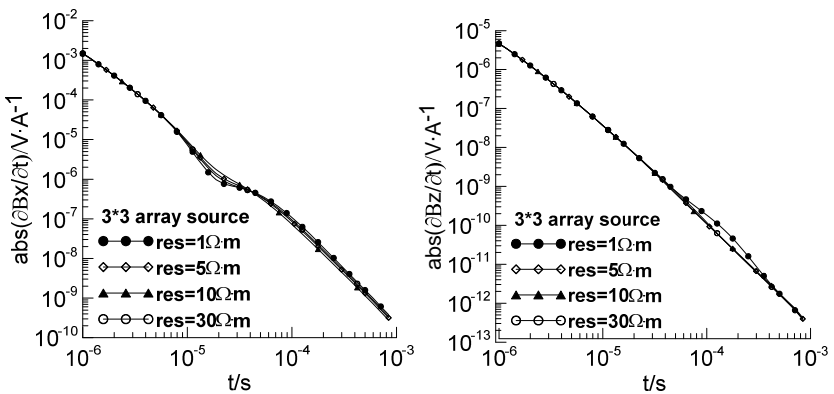

(a) $x$ component

(b) z component

\section{X.CONCLUSIONS}

Through three-dimensional numerical simulation proves that this method has important significance to improve the accuracy of tunnel detection. The array antenna source transient electromagnetic method has better recognition of geological disaster than loop source and the magnetic field three component has anomalous characteristics, meanwhile, a comprehensive analysis of three component features can improve the exploration precision; array source parameters has great influence on response force, we can change array source parameters to increase the response force and improve the signal to noise ratio and resolution. The horizontal component has higher sensitivity than the vertical component; it can improve transient electromagnetic sounding depth through the acquisition of the horizontal component or under the same detection depth condition to improve the transient electromagnetic detection accuracy.

\section{ACKNOWLEDGMENT}

This research is funded by the National Natural Science Foundation of China under the grants (51139004).

\section{REFERENCES}

[1] Li S C, Zhang Q S, "Forecast of karst-fractured ground-water and defective geological conditions", Chinese Journal of Rock Mechanics and Engineering (in Chinese), 2007,26(02),pp. 217-225.

[2] $\mathrm{Li} \mathrm{X}, \mathrm{Wu} \mathrm{J}$ J,Cao D M, "Advanced geological forecasting foe unfavorable geological body with water-transient electromagnetic method", Journal of Geotechnical Investigation \& Surveying (in Chinese).pp. 70-75

Fig. 7 change of resistivity tomography 